\title{
Recovery of spinal cord injury following electroacupuncture in rats through enhancement of Wnt/ $\beta$-catenin signaling
}

\author{
JUNFENG ZHANG, SHISHENG LI and YAOCHI WU \\ Department of Acupuncture, Tuina and Traumatology, \\ The Sixth People's Hospital Affiliated to Shanghai Jiaotong University, Shanghai 200233, P.R. China
}

Received February 23, 2016; Accepted February 23, 2017

DOI: $10.3892 / \mathrm{mmr} .2017 .6801$

\begin{abstract}
Electroacupuncture (EA) has been demonstrated to promote the functional recovery of neurons following spinal cord injury (SCI); however, the mechanisms underlying its effects have yet to be elucidated. The Wnt/ $\beta$-catenin signaling pathway has been implicated in the regulation of the balance between growth, proliferation and differentiation of neural precursor cells. The present study aimed to investigate the effects of EA therapy on Wnt/ $\beta$-catenin-regulated gene expression and neuronal recovery in rats with SCI. The Allen method was used to establish SCI in rats, and alterations in Wnt1 and Nestin mRNA and protein expression levels in response to SCI were determined on days $1,3,7$ and 14 post-injury using reverse transcription-quantitative polymerase chain reaction and western blot analysis. To evaluate the effects of EA treatment on SCI, the following four treatment groups were employed: SCI, SCI + EA, SCI + lithium chloride ( $\mathrm{LiCl})$ and $\mathrm{SCI}+\mathrm{LiCl}+\mathrm{EA}$. The protein expression levels of Wnt1, Nestin and nuclear $\beta$-catenin were evaluated on day 3 post-treatment, and neuronal nuclear antigen $(\mathrm{NeuN})$ protein expression levels were evaluated on day 21 post-treatment using western blot analysis. The Basso, Beattie and Bresnahan scoring method was used to evaluate spinal cord recovery on day 28 post-treatment across the four treatment groups. EA therapy at the Dazhui and Mingmen acupuncture points significantly increased the expression levels of Wnt1, Nestin, $\beta$-catenin and NeuN, thus suggesting that EA therapy may promote spinal cord recovery following injury. The underlying mechanism was demonstrated to involve enhanced $\mathrm{Wnt} / \beta$-catenin signaling, which may promote the proliferation and differentiation of neural stem cells. However, further studies are required to elucidate
\end{abstract}

Correspondence to: Dr Yaochi Wu, Department of Acupuncture, Tuina and Traumatology, The Sixth People's Hospital Affiliated to Shanghai Jiaotong University, 600 Yishan Road, Shanghai 200233, P.R. China

E-mail:wu_ych@yeah.net

Key words: spinal cord injury, electroacupuncture, Wnt/ß-catenin signaling the detailed effects and underlying molecular mechanisms of EA therapy on SCI.

\section{Introduction}

Spinal cord injury (SCI) is a highly disabling insult of the central nervous system (CNS), which can be caused by traffic accidents, falls, violence or sports-related injuries. It can result in the damage of sensory and motor function, autonomic nervous dysfunction, and can have effects on the mental health of patients (1). Recovery following SCI is difficult, due to the complexity of injury pathogenesis, which can include primary and secondary injuries (2). The secondary injury can last for several weeks or months following the initial spinal cord insult, and disturbances in microcirculation (3), neuronal apoptosis and necrosis (4-6), inflammatory response (7) and glial scar (8) may appear during this period. These complications result from neuronal damage, demyelination of axons and dysfunction of neuroglial cells, as the CNS is characterized by limited capability for repair and regeneration (9).

The Wnt/ $\beta$-catenin signaling pathway has been identified as a crucial regulator of the growth and differentiation and survival of neurons (10). Wnt proteins are a large family of signaling proteins, which have been implicated in the regulation of axonal growth, including the long axons of spinal cord neurons (10). $\beta$-catenin is a critical component of the canonical Wnt signaling pathway, which, when activated, can translocate to the nucleus, where it can interact with transcription factors to induce alterations in the expression of target genes (11). The neuronal nuclear antigen (NeuN) is a protein specifically expressed in post-mitotic neurons. $\mathrm{NeuN}$ has been used as a marker of maturing neurons, and has been applied in neuropathological studies to investigate neuronal pathophysiology, as healthy neurons are characterized by strong $\mathrm{NeuN}$ expression, whereas weak $\mathrm{NeuN}$ expression in indicative of degeneration of differentiated neurons (12).

Novel therapeutic approaches are currently being developed for the treatment of patients with SCI, including stem cell therapy $(13,14)$, and electroacupuncture (EA) treatment $(15,16)$. Acupuncture has a long history of use in traditional Chinese medicine, and EA has been reported to promote the proliferation and differentiation of neuronal stem cells (17). Several acupuncture points for EA therapy have been evaluated for their effects on SCI recovery. Choi et al (18) reported that 
acupuncture targeted at Shuigou (GV26) and Yanglingquan (GB34) points significantly alleviated neuronal apoptosis and enhanced their recovery following SCI. Jiang et al (16) compared different modalities of acupuncture at Shuigou (DU26) and Fengfu (DU16) points, and reported anti-inflammatory, antioxidative and anti-apoptotic effects for EA.

Although EA has garnered much attention as a potential therapeutic strategy for the treatment of patients with SCI, its use remains limited, as the mechanisms underlying its beneficial effects have yet to be elucidated. Therefore, the present study aimed to investigate the effects of EA therapy on SCI, and explore the involvement of the $\mathrm{Wnt} / \beta$-catenin pathway in the molecular mechanisms underlying EA-associated neuronal recovery.

\section{Materials and methods}

Animal experiments. Specific pathogen-free male Sprague-Dawley (SD) rats (age, 8 weeks; weight, 250 $\pm 20 \mathrm{~g}$ ) were obtained from Shanghai SLAC Laboratory Animal Co., Ltd. (Shanghai, China). All rats were acclimated in sterile polypropylene cages under an ambient temperature of $25 \pm 2^{\circ} \mathrm{C}$, a relative humidity of $50-60 \%$ and a $12 / 12$ h- dark/light cycle with free access to food and water. Following 1 week of acclimation, rats were randomized into experimental groups. The study was approved by the Ethics Committee of The Sixth People's Hospital Affiliated to Shanghai Jiaotong University (Shanghai, China).

After acclimation, 54 rats were randomly assigned to three groups ( $n=18 /$ group): The SCI group, which included rats that underwent injury at the T9-T11 spinal segment; the sham group, which included rats that received a laminectomy; and the normal group, which included rats that were left untreated. SCI group rats were randomly assigned into day 1,7 and 14 subgroups ( $n=6 /$ group). Rats in the SCI, sham and normal groups were sacrificed on days $1,3,7$ or 14 post-SCI surgery, and spinal cord tissue samples were obtained to assess Wnt1 and Nestin expression.

In EA experiments, 96 rats received SCI surgery and were then randomized into four groups ( $n=24 /$ group): The SCI group, which included rats that were left untreated following SCI surgery; the SCI + EA group, which included rats that received EA treatment lasting 20 min at Dazhui (GV14) and Mingmen (GV4) acupoints every day for 2 weeks following SCI surgery; the $\mathrm{SCI}+\mathrm{LiCl}$ group, which included rats that received an injection of $0.05 \mathrm{ml}$ lithium chloride $(\mathrm{LiCl})(1 \mathrm{~mol} / \mathrm{l})$ at the injured spinal segment every 3 days for 2 weeks following SCI surgery; and the $\mathrm{SCI}+\mathrm{LiCl}+\mathrm{EA}$ group, which included rats that received a $\mathrm{LiCl}$ injection and $\mathrm{EA}$ treatment for 2 weeks following SCI surgery. Tissue samples from the area of SCI were collected from 9 rats in each group and were used to assess the expression of Wnt1, nuclear $\beta$-catenin and Nestin on day 3 of treatment. Tissue samples were collected from another 9 rats in each group and were used to assess the expression of Neuronal Nuclei $(\mathrm{NeuN})$ on day 21 of treatment. The remaining 6 rats in each group were used to evaluate the Basso, Beattie and Bresnahan (BBB) score on day 28 of treatment.

SCI. Moderate SCI was established using the modified Allen method, as previously described (19). Briefly, rats were anesthetized with $10 \%$ chloral hydrate $(3.5 \mathrm{ml} / \mathrm{kg}$, intraperitoneally), then a laminectomy was performed at the T9-T11 level and the spinal cord was exposed without disrupting the dura. Spinous processes of T9 and T11 were stabilized by clamps, and the exposed dorsal surface of the spinal cord was subjected to contusion injury. The force of contusion was $40 \mathrm{~g} \mathrm{x} \mathrm{cm}$ and was generated by a free drop, using Allen's impactor (Peking Union Medical College Microcirculation Institute, Beijing, China). Rats in the sham group only received laminectomy without further intervention. In order to avoid direct contact of the spinal cord wound with air, the wound was covered with cotton soaked in saline. All surgical interventions and postoperative animal care were in line with the guidelines and rules provided by The Sixth People's Hospital Affiliated to Shanghai Jiaotong University.

EA therapy. Rats belonging to the $\mathrm{SCI}+\mathrm{EA}$ and $\mathrm{SCI}+\mathrm{LiCl}+$ EA groups received EA therapy lasting $20 \mathrm{~min}$ each day for 2 weeks. The acupuncture points GV14 (Dazhui) and GV4 (Mingmen) were selected on the basis of clinical acupuncture experience and were located as described in Fig. 1. Stainless steel Hwato brand acupuncture needles $(0.3 \times 25 \mathrm{~mm}$; Suzhou Medical Appliance Factory, Suzhou, China) were inserted at the selected points to a depth of 5-7 $\mathrm{mm}$ and were connected to the output terminals of a G6805-2 EA apparatus (Shanghai Medical Equipment Works Co., Ltd., Shanghai, China). An operating frequency of $2 \mathrm{~Hz}$ and a working current of $1 \mathrm{~mA}$ were used.

Reverse transcription-quantitative polymerase chain reaction $(R T-q P C R)$. Following the last EA treatment, rats were deeply anesthetized with $10 \%$ chloral hydrate and sacrificed. T9-T11 spinal cord segments, containing the injury sites, were dissected and maintained at $-80^{\circ} \mathrm{C}$ until used.

Total RNA was extracted from spinal cord samples using TRIzol ${ }^{\circledR}$ reagent (Invitrogen; Thermo Fisher Scientific, Inc., Waltham, MA, USA). The concentration of extracted RNA was determined using an ultraviolet spectrophotometer. Total RNA (500 ng) was reverse transcribed into cDNA using PrimeScript $^{\text {TM }}$ RT reagent (Takara Bio, Inc., Otsu, Japan). The reaction volume was $20 \mu \mathrm{l}$ and the temperature protocol was as follows: Incubation at $25^{\circ} \mathrm{C}$ for $10 \mathrm{~min}$, at $42^{\circ} \mathrm{C}$ for $30 \mathrm{~min}$, at $95^{\circ} \mathrm{C}$ for $5 \mathrm{~min}$ and at $4^{\circ} \mathrm{C}$ for $5 \mathrm{~min}$. The primers used for PCR were as follows: Wnt1, forward 5'-TACCTCCAGTCA CACTCCCC-3', reverse 5'-CCATGGCAGGAGAATAGG AA-3'; Nestin, forward 5'-GCGGGGCGGTGCGTGACT AC-3', reverse 5'-AGGCAAGGGGGAAGAGAGAAGGAT GT-3'; and GAPDH, forward 5'-ACAGCAACAGGGTGG TGGAC-3' and reverse 5'-TTTGAGGGTGCAGCGAACTT-3'. qPCR was performed using the SYBR PrimeScript RT-PCR kit (Takara Bio, Inc.) with an ABI 7500 Sequence Detection system (Applied Biosystems; Thermo Fisher Scientific, Inc.). The reaction volume was $25 \mu \mathrm{l}$, and contained $12.5 \mu \mathrm{l}$ SYBR-Green mix, $0.5 \mu \mathrm{l}$ of each forward and reverse primer, $2 \mu \mathrm{l}$ cDNA and $9.5 \mu \mathrm{l}$ PCR grade sterile water. Thermocycling conditions were as follows: Initial denaturation at $95^{\circ} \mathrm{C}$ for $3 \mathrm{~min}$, followed by 35 cycles at $95^{\circ} \mathrm{C}$ for $15 \mathrm{sec}$, at $62^{\circ} \mathrm{C}$ for $1 \mathrm{~min}$, and at $72^{\circ} \mathrm{C}$ for $1 \mathrm{~min}$. Each experiment was performed three times. The relative expression levels of each gene were normalized to GAPDH and were calculated using the $2^{-\Delta \Delta C q}$ method (20). 
Western blot analysis. Total proteins from spinal cord tissue samples were extracted using radioimmunoprecipitation assay lysis buffer (Beijing Solarbio Science \& Technology Co., Ltd., Beijing, China) and protein concentrations were determined using bicinchoninic acid assay kits according to the manufacturer's protocol (Thermo Fisher Scientific, Inc.). Equal amounts of protein $(30 \mu \mathrm{g})$ were separated by $10 \%$ SDS-PAGE and transferred onto polyvinylidene difluoride membranes. Membranes were blocked with 5\% non-fat milk in TBS containing $0.1 \%$ Tween-20 for $2 \mathrm{~h}$ at room temperature and then incubated with the following primary antibodies obtained from Abcam (Cambridge, UK): Anti-Wnt1 (cat. no. ab15251; 1:1,000), anti-Nestin (cat. no. ab6142; 1:1,000), anti- $\beta$-catenin (cat. no. ab6302; 1:5,000), anti-NeuN (cat. no. ab177487; 1:1,000) and anti-GAPDH (cat. no. ab8245; 1:1,000) for $12 \mathrm{~h}$ at $4^{\circ} \mathrm{C}$. Membranes were then incubated with goat anti-rabbit horseradish peroxidase-conjugated immunoglobulin $\mathrm{G}$ secondary antibody (cat. no. BA1055; 1:5,000; Wuhan Boster Biological Technology, Ltd., Wuhan, China) for $2 \mathrm{~h}$ at room temperature. Protein bands were visualized using enhanced chemiluminescence detection reagents (Thermo Fisher Scientific, Inc.). The optical densities of the protein bands were semi-quantified using the image analysis system ImageQuant ${ }^{\mathrm{TM}}$ LAS4000mini (GE Healthcare Life Sciences, Chalfont, UK).

$B B B$ score evaluation. In order to examine the functional deficits of SD rats following SCI, the BBB method was employed. Normal male SD rats without functional deficits (BBB score $=21$ ), were selected as a control. Following spinal cord surgery, two trained observers who were blind to the experimental conditions evaluated the grade of each rat according to the BBB open field locomotion test (21). Hindlimb movement, body weight support, foot placement and coordination were observed for $5 \mathrm{~min}$ to determine the BBB score of each animal.

Statistical analysis. The statistical significance of the difference between groups was assessed by one-way analysis of variance, followed by a post hoc least significant difference range test. Data are expressed as the mean \pm standard error of the mean of at least 3 independent experiments. $\mathrm{P}<0.05$ was considered to indicate a statistically significant difference. The analysis was performed using GraphPad Prism software version 5.0 (GraphPad Software, Inc., La Jolla, CA, USA).

\section{Results}

Alterations in $B B B$ score, and Wntl and Nestin levels following SCI. The BBB score has been widely used as a neurological evaluation method, to assess recovery of functionality following SCI $(18,22)$. BBB scores were significantly lower in SCI-treated rats compared with in control and sham rats $(\mathrm{P}<0.01)$, indicating that the rat SCI model was established successfully (Fig. 2).

It has previously been reported that Wnt1 was rapidly induced in the site of injury following SCI, and appeared to serve a role in the regulation of axonal regeneration (23). In the present study, the mRNA and protein expression levels of Wnt1 were assessed on day 1, 7 and 14 following SCI (Fig. 3). When compared with normal and sham rats, the expression of Wnt1 was revealed to be potently and rapidly induced on

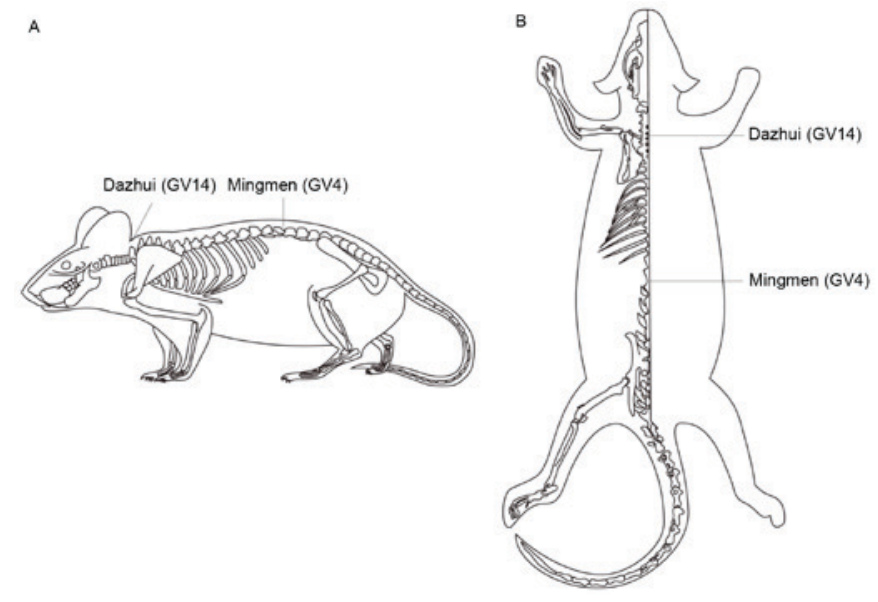

Figure 1. Location of the Dazhui and Mingmen acupuncture points in rats. (A) Side view and (B) vertical view of the rat.

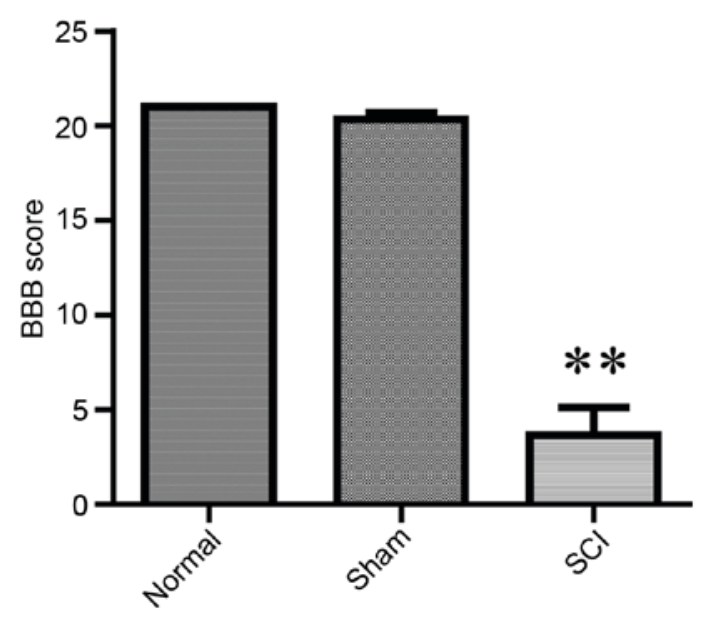

Figure 2. Results of the BBB test in normal, sham and SCI-treated groups on day 7 following SCI surgery. Data are expressed as the mean \pm standard error of the mean; $n=6$ rats/group. ${ }^{* *} \mathrm{P}<0.01$ vs. the normal group. BBB, Basso, Beattie and Bresnahan; SCI, spinal cord injury.

day 1 following SCI; however, it returned to baseline during the following 2 weeks (Fig. 3). These results are in agreement with a previously published report by Liu et al (23).

Nestin is a member of the intermediate filament protein family, and it has been reported to promote the proliferation and self-renewal of neural stem cells (24). The present study examined whether Nestin mRNA and protein expression levels in spinal tissue were altered in response to SCI. In the normal and sham groups, the expression of Nestin remained at low levels (Fig. 4). However, in the SCI group, the expression of Nestin was significantly increased on day 3 following SCI, then returned to baseline levels during the following 2 weeks (Fig. 4). The aforementioned alterations in BBB score, as well as Wntl and Nestin levels, demonstrated that the SCI model was successfully established.

Effects of EA on Wnt1, nuclear $\beta$-catenin and Nestin levels on day 3 following SCI. Wnt1 and nuclear $\beta$-catenin protein expression levels in rats that received EA therapy were significantly increased compared with in untreated rats following 

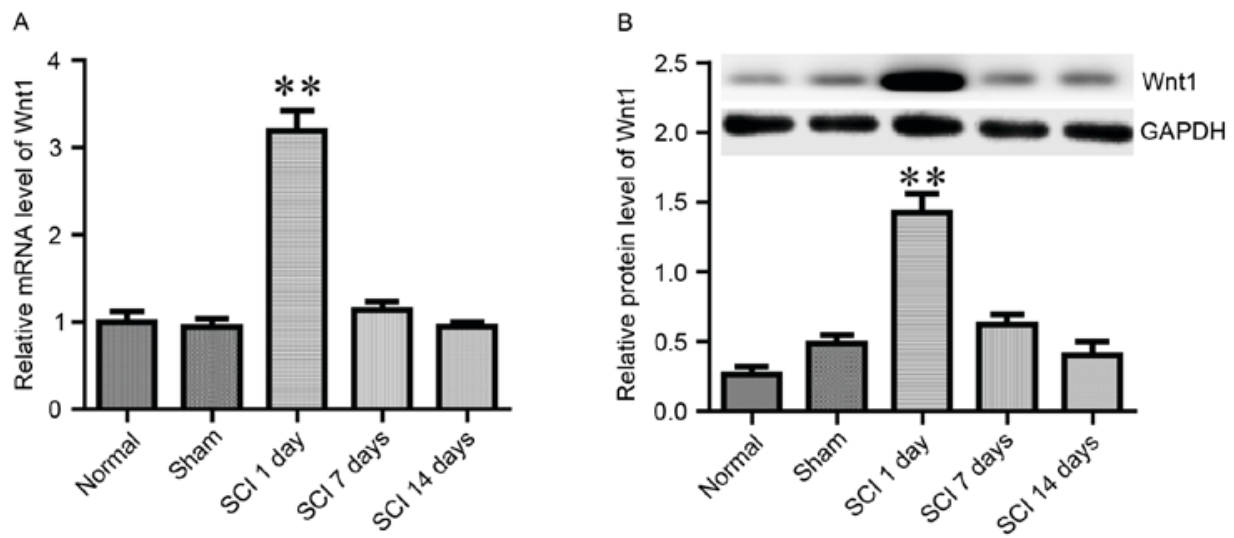

Figure 3. Relative (A) mRNA and (B) protein expression levels of Wnt1 in spinal tissue from rats in the normal, sham and SCI groups, as assessed on days 1, 7 and 14 following SCI. Data are expressed as the mean \pm standard error of the mean; $n=9$ rats/group. ${ }^{* *} \mathrm{P}<0.01$ vs. the normal group. SCI, spinal cord injury.

A

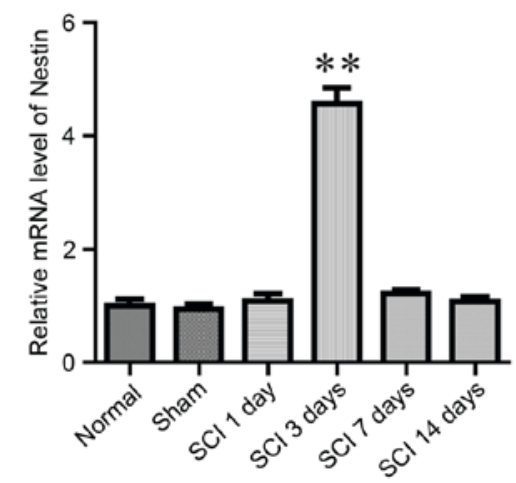

B

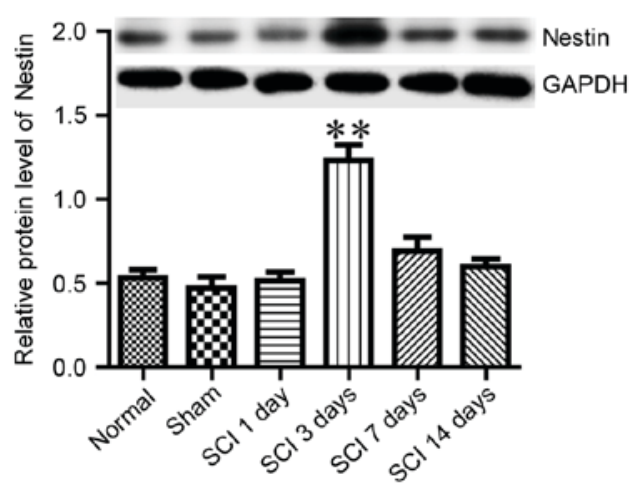

Figure 4. Relative (A) mRNA and (B) protein expression levels of Nestin in spinal tissue from rats in the normal, sham and SCI groups, as assessed on days 1, 3,7 and 14 following SCI. Data are expressed as the mean \pm standard error of the mean; $\mathrm{n}=9$ rats/group. ${ }^{* *} \mathrm{P}<0.01$ vs. the normal group. SCI, spinal cord injury.

SCI $(\mathrm{P}<0.01$; Fig. 5), thus suggesting that EA may enhance $\mathrm{Wnt} / \beta$-catenin signaling. In order to test this hypothesis, SCI rats were treated with $\mathrm{LiCl}$, which inhibits glycogen synthase kinase- $3 \beta$ and thus can potentiate Wnt signaling. Nuclear $\beta$-catenin in the $\mathrm{SCI}+\mathrm{LiCl}$ group appeared significantly upregulated compared with in the SCI group. Furthermore, Wnt1 and nuclear $\beta$-catenin protein levels were significantly higher in SCI rats treated with $\mathrm{EA}$ and $\mathrm{LiCl}$ compared with in rats treated with $\mathrm{LiCl}$ alone (Fig. 5). These results indicated that the mechanism underlying the beneficial effects of EA treatment on SCI may involve the enhancement of Wnt/ $\beta$-catenin signaling.

Nestin expression in spinal tissue was significantly increased on day 3 following SCI in rats receiving EA treatment (Fig. 5). Furthermore, when compared with in LiCl-treated rats, Nestin levels were significantly higher in SCI rats that received a combination of $\mathrm{LiCl}$ and $\mathrm{EA}$ treatment. These results suggested that EA may promote neural recovery following SCI via regulating the expression of Nestin.

Effects of EA on BBB score and NeuN expression on day 21 following SCI. NeuN is a neuron-specific biomarker, and fluctuations in its levels correspond to alterations in neuronal numbers (25). NeuN expression in EA-treated rats was significantly upregulated compared with in SCI untreated rats (Fig. 6A and B). Similarly, rats treated with a combination
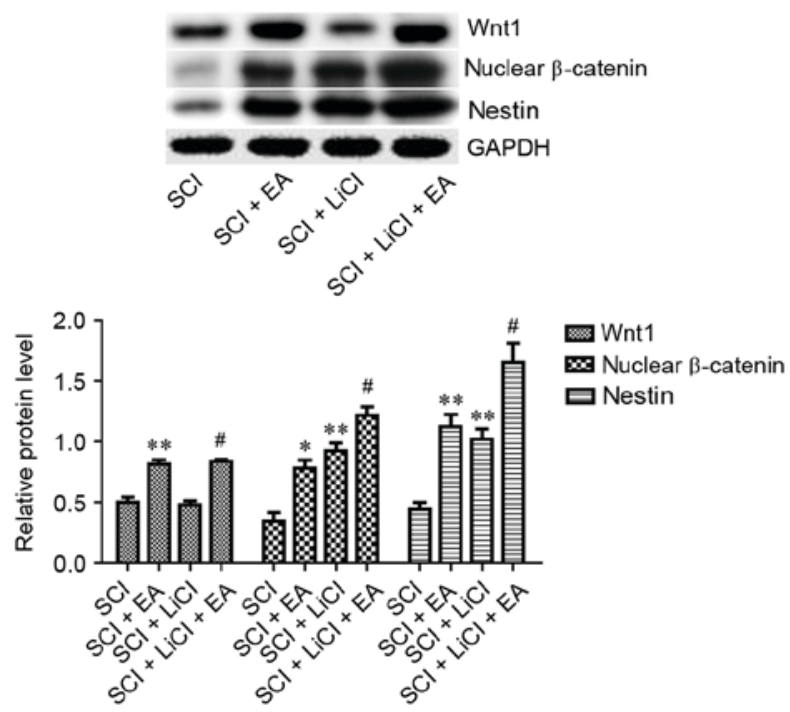

Figure 5. Relative protein expression levels of Wnt1, nuclear $\beta$-catenin and Nestin in spinal tissue from rats in the SCI, SCI + EA, SCI + $\mathrm{LiCl}$ and $\mathrm{SCI}+\mathrm{LiCl}+\mathrm{EA}$ groups, as assessed on day 3 following SCI. Data are expressed as the mean \pm standard error of the mean; $n=9$ rats/group. ${ }^{*} \mathrm{P}<0.05$, ${ }^{* * *} \mathrm{P}<0.01$ vs. the SCI group; ${ }^{\#} \mathrm{P}<0.05$ vs. the $\mathrm{SCI}+\mathrm{LiCl}$ group. SCI group, rats that received SCI and no treatment; SCI + EA group, rats that received $\mathrm{SCI}$ and EA treatment; $\mathrm{SCI}+\mathrm{LiCl}$ group, rats that received $\mathrm{SCI}$ and $\mathrm{LiCl}$ treatment; $\mathrm{SCI}+\mathrm{LiCl}+\mathrm{EA}$ rats that received $\mathrm{SCI}$ and a combination of $\mathrm{EA}$ and $\mathrm{LiCl}$ treatment. SCI, spinal cord injury; EA, electroacupuncture; $\mathrm{LiCl}$, lithium chloride. 
A

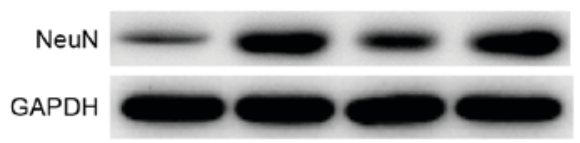

B

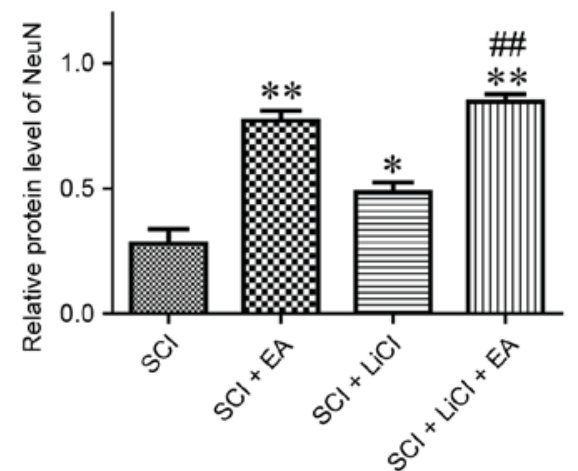

C

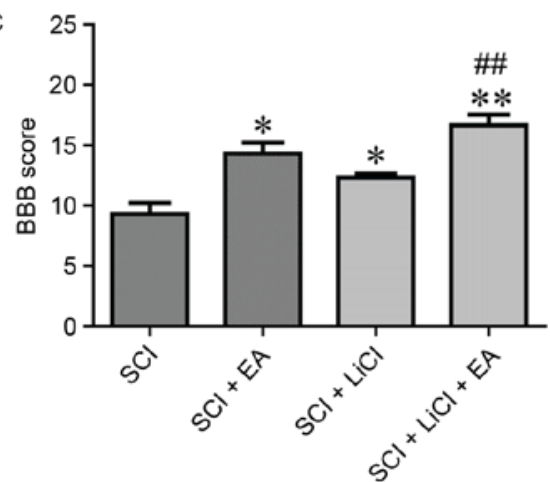

Figure 6. (A) Relative protein expression levels (B) quantifaction of $\mathrm{NeuN}$ in spinal tissue from rats in the $\mathrm{SCI}, \mathrm{SCI}+\mathrm{EA}, \mathrm{SCI}+\mathrm{LiCl}$ and $\mathrm{SCI}+\mathrm{LiCl}+\mathrm{EA}$ groups, as assessed on day 21 following SCI. Data are expressed as the mean \pm standard error of the mean; $\mathrm{n}=9$ rats/group. (C) BBB scores of SCI in rats in the $\mathrm{SCI}, \mathrm{SCI}+\mathrm{EA}, \mathrm{SCI}+\mathrm{LiCl}$ and $\mathrm{SCI}+\mathrm{LiCl}+\mathrm{EA}$ groups, as assessed on day 28 following SCI. Data are expressed as the mean \pm standard error of the mean; $\mathrm{n}=6$ rats/group. ${ }^{*} \mathrm{P}<0.05,{ }^{* *} \mathrm{P}<0.01$ vs. the $\mathrm{SCI}$ group; ${ }^{\# \#} \mathrm{P}<0.01$ vs. the $\mathrm{SCI}+\mathrm{LiCl}$ group. SCI group, rats that received SCI and no treatment; $\mathrm{SCI}+\mathrm{EA}$ group, rats that received SCI and EA treatment; $\mathrm{SCI}+\mathrm{LiCl}$ group, rats that received $\mathrm{SCI}$ and $\mathrm{LiCl}$ treatment; $\mathrm{SCI}+\mathrm{LiCl}+\mathrm{EA}$ rats that received $\mathrm{SCI}$ and a combination of EA and LiCl treatment. NeuN, Neuronal Nuclei; SCI, spinal cord injury; EA, electroacupuncture; LiCl, lithium chloride; BBB, Basso, Beattie and Bresnahan.

of LiCl and EA exhibited significantly higher NeuN levels compared with rats treated with $\mathrm{LiCl}$ alone following SCI (Fig. 6A and B). These results suggested that the observed NeuN upregulation was induced by EA therapy.

On day 28 following SCI, the BBB score was evaluated across all groups. Rats that received EA treatment exhibited significantly higher BBB scores compared with untreated rats following SCI (Fig. 6C). Notably, the effect of EA treatment on the BBB score appeared significantly greater than the effect of $\mathrm{LiCl}$ therapy (Fig. 6C). These results suggested that EA applied at Dazhui and Mingmen points may promote spinal recovery following SCI in rats.

\section{Discussion}

The signaling pathways involved in neuronal recovery and regeneration following SCI have garnered much attention. The Wnt/ $\beta$-catenin signaling pathway, which is highly conserved among multicellular eukaryotic organisms, has been reported to participate in the regulation of cellular proliferation (26), differentiation $(27,28)$, migration (29) and apoptosis $(30,31)$. Several Wnt genes have been identified, including Wnt1, 2, 2b, 3 and 3a. The Wnt family has been reported to serve an important role in the development of the CNS, since it has previously been demonstrated that the $\mathrm{Wnt} / \beta$-catenin signaling pathway promoted the differentiation of neural stem cells into neuronal cells, whereas it inhibited their differentiation into astrocytes $(32,33)$.

In the present study, EA therapy was revealed to upregulate the expression of Wnt1 and nuclear $\beta$-catenin, thus suggesting that EA treatment may enhance Wnt/ $\beta$-catenin signal transduction pathways. The nuclear accumulation of $\beta$-catenin can activate the transcription of genes related to, among others, cellular proliferation and terminal differentiation (34). Nestin is an intermediate filament protein expressed in dividing cells during the early stages of development in the CNS. Upon differentiation, Nestin expression decreases and it is replaced by tissue-specific intermediate filament proteins. In mature organisms, Nestin expression has been revealed to be upregulated under pathological conditions, including glial scar formation following CNS injury (24). In the present study, the expression of Nestin appeared to be upregulated in EA-treated rats compared with in untreated rats following SCI, thus suggesting that EA may promote the proliferation of neural stem cells. In order to further examine whether EA may promote neuronal proliferation, the expression of the neuron-specific marker NeuN (35) was investigated. The present results revealed that EA-treated rats exhibited significantly higher NeuN levels compared with untreated rats following SCI. The increase in Nestin and NeuN expression reported in the present study suggested that EA treatment may promote the differentiation of neural stem cells into neuronal cells in spinal tissue following SCI. Therefore, it may be hypothesized that EA can promote neuronal recovery following SCI, via enhancing Wnt/ $\beta$-catenin signaling and promoting the differentiation of neural stem cells into spinal neurons.

The increased expression of Nestin and NeuN in spinal tissue reported in the present study following EA therapy did not directly reflect alterations in neural stem cell and neuronal cell numbers. In conclusion, in the present study, EA treatment appeared to promote spinal recovery following SCI, via interfering with the Wnt $1 / \beta$-catenin signaling pathway. Furthermore, EA may promote the differentiation of neural stem cells into spinal neurons, via enhancing Wnt1/ $\beta$-catenin signaling; however, further studies are required to investigate this hypothesis.

\section{Acknowledgements}

The present study was supported by the Shanghai Cultivation Plan of New Stars in Xinglin (grant no. ZYSNXD011-RC- 
XLXX-20130046), Lu's Acupuncture Inheritance Study of Shanghai Schools of Traditional Chinese Medicine (grant no. ZYSNXD-CC-HPGC-JD-004) and the Scientific Research Project of Chinese Medicine of Shanghai Health and Family Planning Committee (grant no. 2014LP026B).

\section{References}

1. McDonald JW and Sadowsky C: Spinal-cord injury. Lancet 359: 417-425, 2002.

2. Tator $\mathrm{CH}$ : Update on the pathophysiology and pathology of acute spinal cord injury. Brain Pathol 5: 407-413, 1995.

3. Sekhon LH and Fehlings MG: Epidemiology, demographics, and pathophysiology of acute spinal cord injury. Spine (Phila Pa 1976) 26 (24 Suppl): S2-S12, 2001.

4. Crowe MJ, Bresnahan JC, Shuman SL, Masters JN and Crowe MS: Apoptosis and delayed degeneration after spinal cord injury in rats and monkeys. Nat Med 3: 73-76, 1997.

5. Lou J, Lenke LG, Ludwig FJ and O'Brien MF: Apoptosis as a mechanism of neuronal cell death following acute experimental spinal cord injury. Spinal Cord 36: 683-690, 1998.

6. Osterholm JL and Mathews GJ: Altered norepinephrine metabolism following experimental spinal cord injury. 1. Relationship to hemorrhagic necrosis and post-wounding neurological deficits. J Neurosurg 36: 386-394, 1972.

7. Donnelly DJ and Popovich PG: Inflammation and its role in neuroprotection, axonal regeneration and functional recovery after spinal cord injury. Exp Neurol 209: 378-388, 2008.

8. Tysseling-Mattiace VM, Sahni V, Niece KL, Birch D, Czeisler C, Fehlings MG, Stupp SI and Kessler JA: Self-assembling nanofibers inhibit glial scar formation and promote axon elongation after spinal cord injury. J Neurosci 28: 3814-3823, 2008.

9. Gajos-Michniewicz A and CzyzM: Modulation of WNT/ $\beta$-catenin pathway in melanoma by biologically active components derived from plants. Fitoterapia 109: 283-292, 2016.

10. Liu YB, Wang XF, Lu CC, Sherman R, Steward O, Xu XM and Zou Y: Repulsive Wnt signaling inhibits axon regeneration after CNS injury. J Neurosci 28: 8376-8382, 2008.

11. Zechner D, Fujita Y, Hülsken J, Müller T, Walther I, Taketo MM, Crenshaw EB III, Birchmeier W and Birchmeier C: beta-Catenin signals regulate cell growth and the balance between progenitor cell expansion and differentiation in the nervous system. Dev Biol 258: 406-418, 2003.

12. Lavezzi AM, Corna MF and Matturri L: Neuronal nuclear antigen (NeuN): A useful marker of neuronal immaturity in sudden unexplained perinatal death. J Neurol Sci 329: 45-50, 2013.

13. Obermair FJ, Schröter A and Thallmair M: Endogenous neural progenitor cells as therapeutic target after spinal cord injury. Physiology (Bethesda) 23: 296-304, 2008.

14. Okano H, Ogawa Y, Nakamura M, Kaneko S, Iwanami A and Toyama Y: Transplantation of neural stem cells into the spinal cord after injury. Semin Cell Dev Biol 14: 191-198, 2003.

15. Yan Q, Ruan JW, Ding Y, Li WJ, Li Y and Zeng YS: Electro-acupuncture promotes differentiation of mesenchymal stem cells, regeneration of nerve fibers and partial functional recovery after spinal cord injury. Exp Toxicol Pathol 63: 151-156, 2011.

16. Jiang SH, Tu WZ, Zou EM, Hu J, Wang S, Li JR, Wang WS, He R, Cheng RD and Liao WJ: Neuroprotective effects of different modalities of acupuncture on traumatic spinal cord injury in rats. Evid Based Complement Alternat Med 2014: 431580, 2014.

17. Chen YY, Zhang W, Chen YL, Chen SJ, Dong H and Zeng YS: Electro-acupuncture improves survival and migration of transplanted neural stem cells in injured spinal cord in rats. Acupunct Electrother Res 33: 19-31, 2008.
18. Choi DC, Lee JY, Moon YJ, Kim SW, Oh TH and Yune TY: Acupuncture-mediated inhibition of inflammation facilitates significant functional recovery after spinal cord injury. Neurobiol Dis 39: 272-282, 2010.

19. Faden AI and Simon RP: A potential role for excitotoxins in the pathophysiology of spinal cord injury. Ann Neurol 23: 623-626, 1988.

20. Livak KJ and Schmittgen TD: Analysis of relative gene expression data using real-time quantitative PCR and the 2(-Delta Delta C(T)) method. Method 25: 402-408, 2001.

21. Basso DM, Beattie MS and Bresnahan JC: A sensitive and reliable locomotor rating scale for open field testing in rats. J Neurotrauma 12: 1-21, 1995.

22. Lee SM, Yune TY, Kim SJ, Park DW, Lee YK, Kim YC, Oh YJ, Markelonis GJ and Oh TH: Minocycline reduces cell death and improves functional recovery after traumatic spinal cord injury in the rat. J Neurotrauma 20: 1017-1027, 2003.

23. Liu Y, Wang X, Lu CC, Kerman R, Steward O, Xu XM and Zou Y: Repulsive Wnt signaling inhibits axon regeneration after CNS injury. J Neurosci 28: 8376-8382, 2008.

24. Park D, Xiang AP, Mao FF, Zhang L, Di CG, Liu XM, Shao Y, Ma BF, Lee JH, Ha KS, et al: Nestin is required for the proper self-renewal of neural stem cells. Stem Cells 28: 2162-2171, 2010.

25. Mullen RJ, Buck CR and Smith AM: NeuN, a neuronal specific nuclear protein in vertebrates. Development 116: 201-211, 1992.

26. Dravid G, Ye Z, Hammond H, Chen G, Pyle A, Donovan P, Yu X and Cheng L: Defining the role of Wnt/beta-catenin signaling in the survival, proliferation, and self-renewal of human embryonic stem cells. Stem Cells 23: 1489-1501, 2005

27. Hirabayashi Y, Itoh Y, Tabata H, Nakajima K, Akiyama T, Masuyama N and Gotoh Y: The Wnt/beta-catenin pathway directs neuronal differentiation of cortical neural precursor cells. Development 131: 2791-2801, 2004.

28. Day TF, Guo X, Garrett-Beal L and Yang Y: Wnt/beta-catenin signaling in mesenchymal progenitors controls osteoblast and chondrocyte differentiation during vertebrate skeletogenesis. Dev Cell 8: 739-750, 2005.

29. Aman A and Piotrowski T: Wnt/beta-catenin and Fgf signaling control collective cell migration by restricting chemokine receptor expression. Dev Cell 15: 749-761, 2008.

30. Chen S, Guttridge DC, You Z, Zhang Z, Fribley A, Mayo MW, Kitajewski $\mathrm{J}$ and Wang C: Wnt-1 signaling inhibits apoptosis by activating beta-catenin/T cell factor-mediated transcription. J Cell Biol 152: 87-96, 2001.

31. Almeida M, Han L, Bellido T, Manolagas SC and Kousteni S: Wnt proteins prevent apoptosis of both uncommitted osteoblast progenitors and differentiated osteoblasts by beta-catenin-dependent and-independent signaling cascades involving Src/ERK and phosphatidylinositol 3-kinase/AKT. J Biol Chem 280: 41342-41351, 2005.

32. Wang F, Huang Q, Lan Q and Li ST: Expression of Wnt-1 gene in the course of th human embrynoic neural stem cells differentiating into neurons. Chinese Journal of Neurosurgery 20: 409-412, 2005.

33. Davidson KC, Adams AM, Goodson JM, McDonald CE, Potter JC, Berndt JD, Biechele TL, Taylor RJ and Moon RT: Wnt/ $\beta$-catenin signaling promotes differentiation, not self-renewal, of human embryonic stem cells and is repressed by Oct4. Proc Natl Acad Sci USA 109: 4485-4490, 2012.

34. Clevers H: Wnt/beta-catenin signaling in development and disease. Cell 127: 469-480, 2006.

35. Wolf HK, Buslei R, Schmidt-Kastner R, Schmidt-Kastner PK, Pietsch T, Wiestler OD and Blümcke I: NeuN: A useful neuronal marker for diagnostic histopathology. J Histochem Cytochem 44: $1167-1171,1996$. 